\title{
Improving the Usage of Industrialized Building Systems in the South African Construction Industry: Principal Component Analysis Approach
}

\author{
Emmanuel, O, Ayorinde \\ Department of Civil Engineering \\ Technology, University of \\ Johannesburg, South Africa \\ eayorinde@uj.ac.za
}

\author{
Ntebo, Ngcobo \\ Department of Civil Engineering \\ Technology, University of \\ Johannesburg, South Africa \\ ntebon@uj.ac.za
}

\author{
Mathe, Kasenge \\ Department of Civil Engineering \\ Technology, University of \\ Johannesburg, South Africa \\ mkasenge@uj.ac.za
}

\begin{abstract}
The construction industry $(\mathrm{CI})$ is the main driver of sustainable development (SD) and economic expansion in society. Industrialized building systems (IBS) promote productivity and improves quality on construction sites. The purpose of this study is to investigate ways of improving the use of IBS in the SACI. For this study, data was collected using primary and secondary sources of data collection. The study adopted a quantitative research approach with data gathered from the respondents within SACI. The findings revealed that the most significant ways of improving IBS use in SACI are government incentives towards IBS supporting projects, specialized training for IBS contractors, and improving the educational curriculum to include IBS methods. Construction waste is a by-product of construction demolition and renovation and has caused adverse effects on the environment. Therefore, one of the way to mitigate such environmental hazards is to use IBS. This study will contribute greatly to sustainable construction delivery in South Africa, socio-economic growth and will aid fast delivery of construction projects in terms of cost, time, and quality. Also, construction waste hazards causing harm to the environment can be reduced with the correct implementation of IBS in society.

CCS CONCEPTS •Applied engineering •medium relevance
\end{abstract}

\section{KEYWORDS}

Industrialized building systems, Economic growth, Sustainability, Construction industry

\section{ACM Reference Format:}

Emmanuel, O, Ayorinde, Ntebo, Ngcobo, and Mathe, Kasenge. 2021. Improving the Usage of Industrialized Building Systems in the South African Construction Industry: Principal Component Analysis Approach. In 2021 The 11th International Conference on Information Communication and Management (ICICM 2021), August 12-14, 2021, Tokyo, Japan. ACM, New York, NY, USA, 4 pages. https://doi.org/10.1145/3484399.3484418

This work is licensed under a Creative Commons Attribution International 4.0 License.

ICICM 2021, August 12-14, 2021, Tokyo, fapan

(c) 2021 Copyright held by the owner/author(s).

ACM ISBN 978-1-4503-9019-4/21/08.

https://doi.org/10.1145/3484399.3484418

\section{INTRODUCTION}

The SACI plays an important part in wealth generation in the country and promotes society's development and socio-economic indices [1]. The construction industry has remained the highest employer of labor in the country, employing an estimated 1.4 million people in 2012 [1]. Despite this great repute, the construction projects always run into time overrun.

This limitation brought forth the adoption of IBS as a medium to cut construction costs, better health and safety measures, and ensure faster delivery of civil engineering projects to society [2]. The desired project delivery time with great quality is channeled to society via IBS. IBS refers to civil structures that are produced under a controlled environment and installed correctly on site. The adoption of IBS in the construction industry has helped to halt the environmental hazard associated with the by-product of civil works, which has caused a lot of damage to the environment [3]. The process of IBS includes the production stage, the delivering stage, and the installation stage to produce the final product. The benefits of IBS over the conventional means of construction are enormous. One of the benefits of IBS construction is that it is not dependent on the weather since the components of the proposed structure are constructed away from the site and only transported to site for proper installations [4].

The SACI plays a dynamic position in the socio-economic development in SA, and contributes significantly to the GDP of the country [5]. The concept IBS means faster project delivery and efficiency. The industrialized process promotes the investment in construction equipment, facilities, and technology to maximize production output, thereby reducing labor resources and enhancing quality, while building systems is a set of related elements that joins together to enable the designated performance of a building [6]. In order to get buy-in from stakeholders regarding the use of IBS, specific measures need to be put in place and implemented. Specialized training of the construction industry personnel on the use of IBS will ensure that massive numbers of unskilled personnel in the industry can undertake IBS production [7]. There must also be an increase in awareness campaigns on the benefits of using IBS [8]. There should be favorable policies by the government to encourage IBS contractors and introduce new technology for IBS by the government [9].

\section{METHODOLOGY}

The method used in this study was a quantitative research approach to achieve the aim of the study, which is to improve the usage of IBS 
Table 1: Encouraging the use of IBS in SACI

\begin{tabular}{|c|c|c|c|}
\hline Measures to encourage the increase use of IBS within the South African construction industry & Mean & $\begin{array}{l}\text { Standard } \\
\text { Deviation }\end{array}$ & Rank \\
\hline Increased awareness on IBS benefits & 4.53 & 0.578 & 1 \\
\hline Government incentives on IBS supporting projects & 4.51 & 0.644 & 2 \\
\hline Specialised Training courses on IBS for contractors & 4.45 & 0.610 & 3 \\
\hline Improving the educational curriculum to include IBS methods & 4.45 & 0.730 & 3 \\
\hline Enforce utilisation of IBS for $30 \%$ of total government projects & 4.37 & 0.894 & 5 \\
\hline Provide tax incentives for manufactures of IBS & 4.33 & 0.739 & 6 \\
\hline Favorable Government policies & 4.31 & 0.836 & 7 \\
\hline Continual improvement in IBS for more flexible design & 4.16 & 0.857 & 8 \\
\hline
\end{tabular}

This is example of table footnote.

in the SACI. Quantitative methods relate to positivism and factual data [10]. The questionnaire was developed from a comprehensive review of the literature and is not part of any existing survey instrument. Practicing professionals in the SACI were engaged in the collection of the primary data on the improved usage of IBS in the SACI.

The Likert scale (strongly agree $=5$, agree $=4$, neutral $=3$, disagree $=4$, strongly disagree $=5$ ) Mean item score (MIS) was used to present the research findings from the Likert scale in decreasing order.

Exploratory factor analysis (EFA) is one of the two types of factor analysis (FA), and is often deployed during the initial stage of research by researchers in order to collate information about the interrelationships within a set of variables [11]. The EFA of the results was obtained to confirm the validity and reliability of the improved usage of IBS in the SACI, with the highest likelihood having an eigen value of more than one, together with the varimax rotation. EFA was explicitly used for this study. SPSS software version 21.0 was used to conduct the EFA for this research. The descriptive results show the rankings of all the factors from the first to last according to the variables, with the table representing the individual variables' mean score as well as the standard deviation of the variables.

Data analysis. Two descriptive statistics were carried out, which are in the form of mean item score and factor analysis. The ranking of the variables was done with mean item score. Likewise, factor analysis was carried out to outline the variables measuring the same underlying effects [12].

Mean Item Score. The mean ranking of the variables presented depicts the individual views reached by the respondents. The result for the test is shown in the table below. The mean table represented below also includes the standard deviation of the variables.

Results from Exploratory Factor Analysis. The EFA results on measures to encourage the increased use of IBS within the SACI are depicted in Tables 1, 2, 3, 4, and Fig. 1. Out of the total of eight variables outlined, none of the variables were missing. The following are the complete eight variables identified with the potential of encouraging the increased usage of IBS within the SACI.

Factor Analysis. Factor analysis is vital in breaking down numbers of large variables and breaking them into more simple clusters for better interpretations [13]. Tables 2-4 and Fig. 1 below show Kaizer-Meyer-Olkin (KMO), the measure of sampling adequacy attained a high score of 0.748 . The Bartlett test of sphericity also was important; this suggests that the matrix of the population is not an identical matrix. In addition, the Cronbach alpha that measures internal consistency is 0.682 , thus suggest that the reliability of the instrument used by the researcher in the research is quite good. Data was regulated with principal component analysis (with varimax rotation). The eigen value has a high value of more than 1 . As represented in Table 4 and Fig. 1, the factor loading extracted were eight components with the eigenvalue between 0.5 and 1 (also see Fig. 1 scree plot). For the total variance (see Table 4), as explained by each component extracted, component 1 (46.119), component 2 (15.509). Therefore, the result from the principal component analysis (PCA) and the factors extracted amounted to $61.628 \%$ of the total cumulative variance.

The principal axis factoring used showed that two (2) were present with eigenvalue greater than 1 as represented in Table 4 above. Owing to the careful observation of the inherent connections among each of the variables under each factor, the following assessments were made: Factor 1 was described as IBS sensitization mechanics, and factor 2 was described as IBS legislation effects. The term used in describing these factors was obtained as a result of closely observing the variables within each of the factors. The two factors extracted and their constituent indicators are explained below, together with a comprehensive description on how the two factors were described in the factor section.

\section{DISCUSSION OF RESULT}

Factor 1: IBS Sensitization Mechanics. As shown in Table 3 above, the four extracted measures to encourage IBS usage within the SACI for factor 1 were specialized training courses on IBS for contractors (87.3\%), Increase awareness on IBS benefits (84.2\%), Government incentives on IBS supporting projects (81.3\%), Improving the educational curriculum to include IBS methods (58.7\%). The number in the parenthesis shows the individual factor loadings. The definition of these variables are also explained in Table 2. This cluster accounted for $46.119 \%$ of the variance.

Factor 2: IBS Legislation Effects. As shown in Table 3 above, the three (4) extracted measures to encourage IBS usage within the 
Table 2: KMO and Bartlett's test

\begin{tabular}{lll}
\hline Kaiser-Meyer measure of sampling adequacy & Mean & .682 \\
\hline Bartlett's test of sphericity & Approx. chi-square & 175.383 \\
& df & 28 \\
& Sig. & .000 \\
\hline
\end{tabular}

Table 3: Rotated factor matrix

\begin{tabular}{lcc}
\hline Factor Matrix & Factor \\
\hline & 1 & 2 \\
Specialized training courses on IBS for contractors & .873 & .842 \\
Increase awareness of IBS benefits & .814 & .587 \\
Government incentives on IBS supporting projects & .882 \\
Improving the educational curriculum to include IBS methods & .781 \\
Provide tax incentives for manufactures of IBS & .624 \\
Favorable government policies & .562 \\
Enforce utilisation of IBS for 30\% of total government projects & \\
Continual improvement in IBS for more flexible design & \\
\hline
\end{tabular}

Table 4: Total variance explained

\begin{tabular}{|c|c|c|c|c|c|c|c|c|c|}
\hline \multirow[t]{2}{*}{ Factors } & \multicolumn{3}{|c|}{ Initial eigenvalues } & \multicolumn{3}{|c|}{$\begin{array}{l}\text { Extraction sums of squared } \\
\text { loadings }\end{array}$} & \multicolumn{3}{|c|}{ Rotated sums of squared loadings } \\
\hline & Total & $\%$ of & Total & Total & $\begin{array}{c}\% \text { of } \\
\text { Variance }\end{array}$ & $\begin{array}{c}\text { Cumulative } \\
\%\end{array}$ & Total & $\begin{array}{c}\% \text { of } \\
\text { Variance }\end{array}$ & $\begin{array}{c}\text { Cumulative } \\
\%\end{array}$ \\
\hline 1 & 3.689 & 46.119 & 46.119 & 3.689 & 46.119 & 46.119 & 46.119 & 2.648 & 33.103 \\
\hline 2 & 1.241 & 15.509 & 61.628 & 1.241 & 15.509 & 61.628 & 61.628 & 2.282 & 28.525 \\
\hline 3 & 0.945 & 11.818 & 73.446 & & & & & & \\
\hline 4 & 0.851 & 10.640 & 84.086 & & 4.45 & 0.730 & & & \\
\hline 5 & .598 & 7.471 & 91.557 & & 4.37 & 0.894 & & & \\
\hline 6 & .266 & 3.325 & 94.882 & & 4.33 & 0.739 & & & \\
\hline 7 & .256 & 3.199 & 98.081 & & 4.31 & 0.836 & & & \\
\hline 8 & .154 & 1.919 & 100.000 & & 4.16 & 0.857 & & & \\
\hline \multicolumn{10}{|c|}{ Extraction method: Principal axis factoring } \\
\hline
\end{tabular}

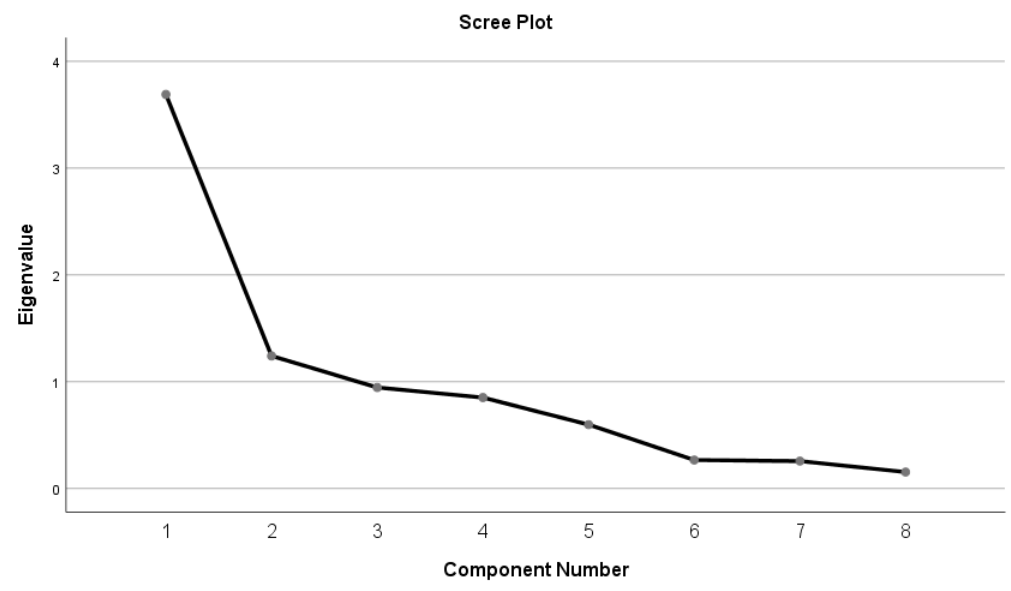

Figure 1: Scree plot for factor analysis 
SACI for factor 2 were Provide tax incentives for manufacturers of IBS $(88.2 \%)$, Favourable Government policies $(78.1 \%)$, Enforce utilisation of IBS for $30 \%$ of total government projects $(62.4 \%)$ and Continual improvement in IBS for more flexible design (56.2\%) . The numbers in the parenthesis show the individual loadings. The definitions of these variables are also explained in Table 2 above. This cluster accounted for $15.109 \%$ of the variance.

\section{IMPLICATIONS OF FINDINGS}

The review of literature conforms to the findings of this study and is evidenced in the empirical study, which reveals that the measures to encourage the increased use of IBS within SACI are from increase awareness on IBS benefits, government incentives on IBS supporting projects, Specialised Training courses on IBS for contractors, improving the educational curriculum to include IBS methods. Therefore, it is imperative for SACI to adopt IBS for sustainable development i.e. economic and social relevance. This is because, according to the existing literature, to experience the improved usage of IBS within SACI there must be steps taking as evident in the literature.

\section{CONCLUSION}

Results from the literature review show that current measures to encourage the use of IBS within SACI should be enhanced. The literature further shows that other mechanisms of awareness about the use of IBS can be used.

Results from the findings of the secondary data (questionnaire survey) indicate that there are five main measures that can be used to encourage the use of IBS within SACI. These include increased awareness on IBS benefits, government incentives on IBS supporting projects, specialised training courses on IBS for contractors, improving the educational curriculum to include IBS methods and
Enforce utilisation of IBS for $30 \%$ of total government projects. It can be said conclusively that this research objective for this study has been answered.

\section{REFERENCES}

[1] Lou, E.C.W. and Kamar, K.A.M., Industrialized building systems: Strategic outlook for manufactured construction in Malaysia. Journal of Architectural Engineering, 18(2), pp.69-74. (2012).

[2] Warszawski, A., Industrialized and automated building systems: A managerial approach. Routledge. (2003)

[3] Din, M.I., Bahri, N., Dzulkifly, M.A., Norman, M.R., Kamar, K.A.M. and Hamid, Z.A., The adoption of Industrialised Building System (IBS) construction in Malaysia: The history, policies, experiences and lesson learned. In ISARC. Proceedings of the International Symposium on Automation and Robotics in Construction (Vol. 29, p. 1). Vilnius Gediminas Technical University, Department of Construction Economics \& Property, pp. 26 (2012).

[4] Haas, C.T., O’Connor, J.T., Tucker, R.T., Eickmann, J.A. and Fagerlund, W.R., Prefabrication and preassembly trends and effects on the construction workforce. Center for Construction Industry Studies, pp. 14, (2000).

[5] Kamar, A.M., Hamid, Z.A. and Azman, N.A., Industrialized building system (IBS): Revisiting issues of definition and classification. International journal of emerging sciences, 1(2), pp.120. (2011).

[6] Begum, R.A., Satari, S.K. and Pereira, J.J., Waste generation and recycling: Comparison of conventional and industrialized building systems. American Journal of Environmental Sciences, 6(4), p.383. (2010).

[7] Saggaff, A., Industrialized building system-an innovative construction method. In MATEC Web of Conferences (Vol. 101, p. 05001). EDP Sciences, pp.2-3, (2017).

[8] Rahman, A.B.A. and Omar, W., Issues and challenges in the implementation of industrialized building systems in Malaysia. In Proceedings of the 6th Asia-Pacific Structural Engineering and Construction Conference, APSEC 2006, pp. 5-6 (2006)

[9] Windapo, A.O., Skilled labour supply in the South African construction industry: The nexus between certification, quality of work output and shortages. SA Journal of Human Resource Management, 14(1), pp.1-8. (2016).

[10] Burns, N. \& Grove, S.K. The practice of nursing research. Conduct, critique \& utilization, 4th edition. Philadelphia: W. B. Saunders, (1993).

[11] Pallant, J. Multivariate analysis of variance. SPSS survival manual. Allen \& Unwin. (2011).

[12] B Ledwaba, M.J. Informal settlements and organisations in post-apartheid South Africa: The case of Bethlehem, Tshwane (Mini dissertation). (2012). Available online at: http://hdl.handle.net/10210/532.[Accessed 27 February 2019].

[13] Ahadzie D, Proverbs D, Olomolaiye P. Critical success criteria for mass house building projects in developing countries. International Journal of Project Management. Pp-26(6):675-87, Aug 31, (2008) 